\title{
Lithium Disilicate (E-Max Press) Based Crowns for Esthetic Rehabilitation in Esthetic Zone: A Case Report
}

\author{
Alalkhashab $\mathbf{M}^{*}$ \\ Department of Restorative dentistry, Aseer Specialist Dental Center, Kingdom of Saudi \\ Arabia \\ *Corresponding author: Alalkhashab Mohammed, Senior registrar, Department of \\ Restorative dentistry, Aseer Specialist Dental Center, Abha, Kingdom of Saudi Arabia, \\ Email: dr.alkhashab@gmail.com
}

\section{Case Report}

Volume 3 Issue 2

Received Date: April 28, 2018

Published Date: May 08, 2018

DOI: $10.23880 /$ oajds-16000178

\section{Abstract}

Today, patients are increasingly interested in metal-free restorations. Glass-ceramics are particularly suitable for fabricating all ceramic crowns which have the potential to mimic natural teeth characteristics and achieve very pleasant, esthetic outcome. This case report highlights the rehabilitation of esthetic smile that was compromised due to defective old metal ceramic crowns with poor design that lead to periodontal inflammation and poor esthetics. In esthetic zone, Incisors, canines and premolars were restored with Lithium disilicate (E-max press) using lost wax technique.

Keywords: Esthetic all ceramic restoration; Lithium disilicate; Lost wax technique; Pressing technique

\section{Introduction}

Glass-ceramics are widely used as biomaterials for dental restoration especially crowns and short fixed dental prosthesis. Re-establishment of proper esthetics and function in the anterior region is a real challenge for the dentist in order to provide an esthetic, pleasing and natural appearing like life smile and functional restoration during phonation and mastication. All-ceramic crowns can be made from different types of ceramics and not all ceramic types have the same physical and esthetic proprieties [1].

The technology of bonding porcelain created the possibility for glace ceramics to be used in full crowns for the treatment of many clinical conditions. Lithium disilicate, one of the high end all ceramic esthetics material, helps in achieving more esthetically pleasing restoration making it replace the time-tested metal ceramic restorations [2,3]. Improvements in dental materials have made ceramic a desirable option for indirect esthetic restorative procedures [4,5]. Ceramics have compressive strength, surface smoothness, abrasion resistance, gloss, and low plaque accumulation [6,7].

\section{Case Report}

A 25 year old healthy female patient reported for restoring her maxillary teeth at the Restorative department with chief complaint of bleeding gums with ugly dark crowns and asked for an esthetic smile.

The clinical examination and history revealed that the patient was within normal upon extra-oral examination. On intra-oral examination showed a Periodontal inflammation with increased probing depth $(4 \mathrm{~mm})$, related to the old anterior crowns and presence of caries and defective restorations. The gingiva was hyperemic and chronically inflamed. Bleeding on minimal probing was evident. The diagnosis was a chronic generalized marginal gingivitis. Her oral hygiene was insufficient with no pockets in the posterior segments (Figure 1). 


\section{Open Access Journal of Dental Sciences}

Radiographic examination revealed asymptomatic apical periodontitis (Figure 2).

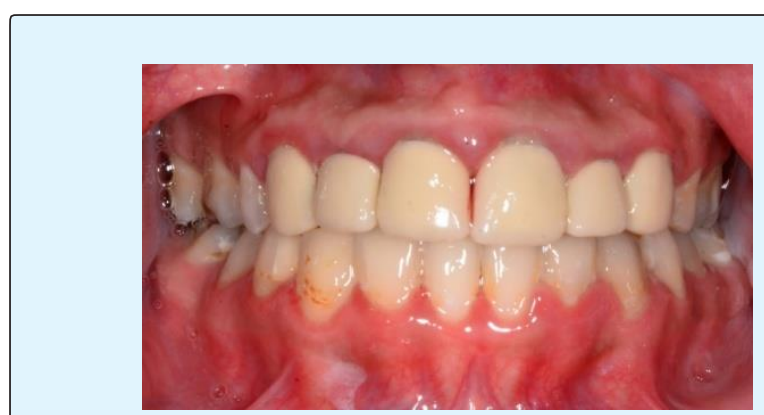

Figure 1: Pre-operative frontal view showing metalceramic crowns with inappropriate ratios and shade.

Esthetic correction with glass ceramic (IPSe.max Press, IvoclarVivadent) for maxillary teeth (incisors, canines and premolars) was planned. After clinical examination, radiographs, photographs (Figure 3), impressions were made and mounted diagnostic wax-up (Figures $4 \& 5$ ) was performed taking into consideration the proper crown length to width ratios.

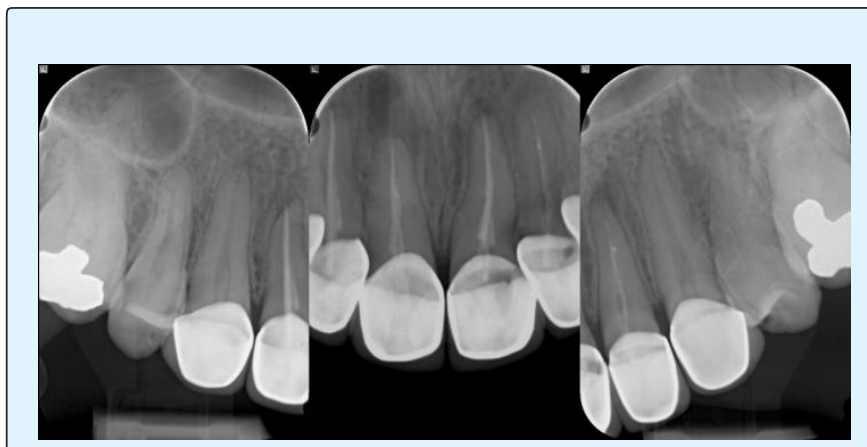

Figure 2: Pre-operative radiographs showing periapical periodontitis related to teeth \#12, 11, 21 \& 22.

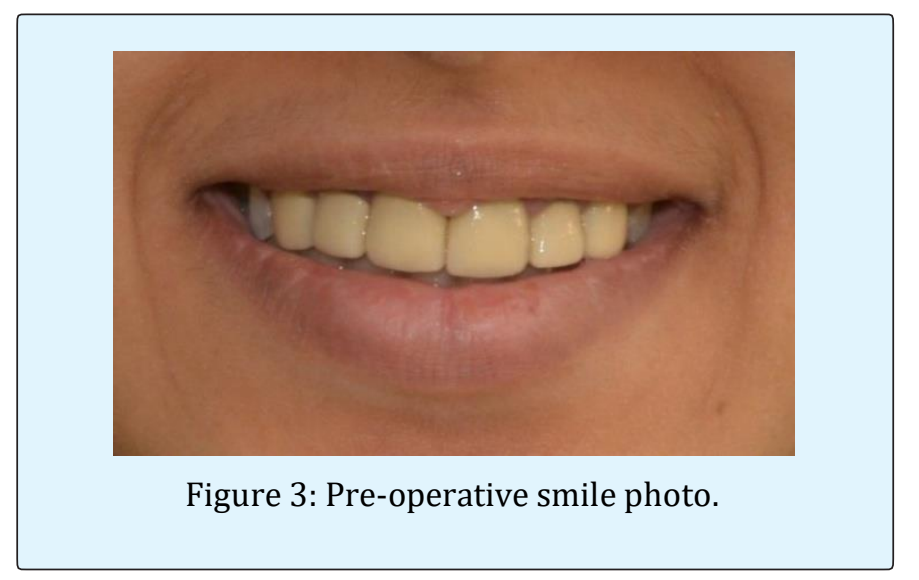

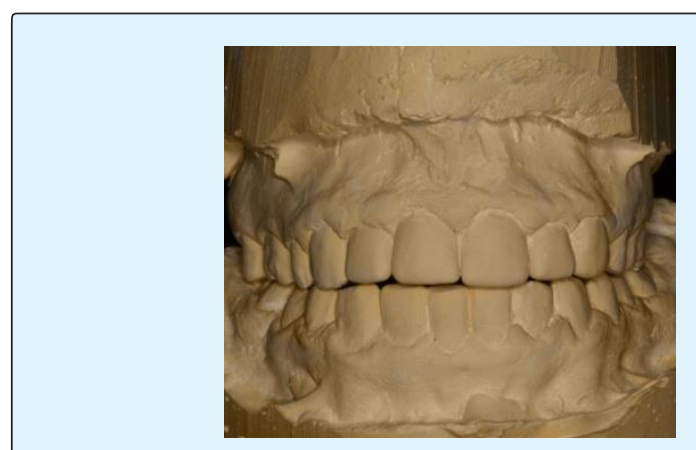

Figure 4: Mounted study model.

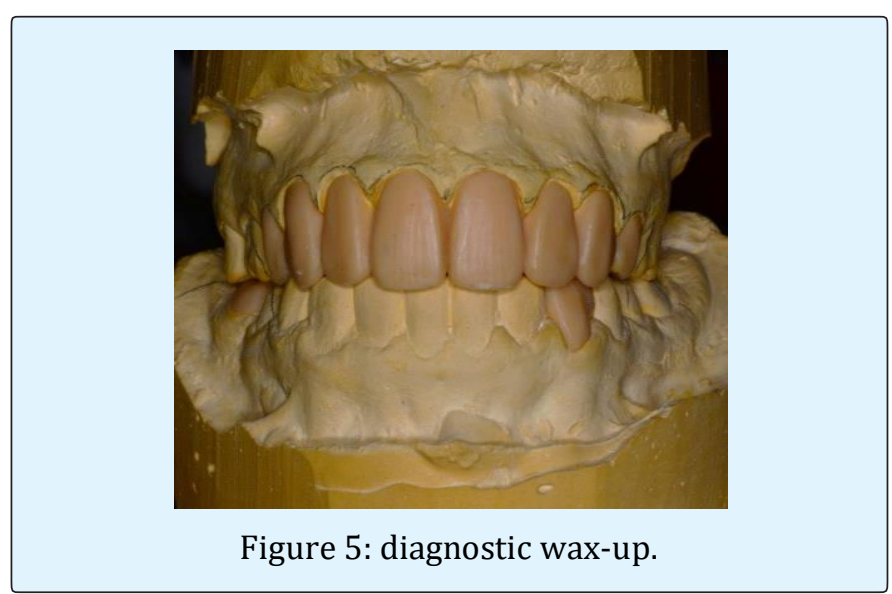

Two putty indices were made; one was used to guide the esthetic Gingivectomy and thereby verify the proper reduction. The other was used to perform interim crowns. First, the patient was recommended to take up initial periodontal preparation and to intensify oral hygiene before starting the rehabilitation process [8]. Second, the old crowns were removed using sectioning using diamond burs to cut through ceramic and fissure bur to cut through the metal. Sectioning was decided to avoid damaging the remaining tooth structure and this decision was encouraged by the fact that the wax-up based temporary crowns will look better than the existing restorations and give the patient an impression about the increased length of the crowns to give an appropriate length to width ratio. Then, adjustment of the preparations was done; the treatment protocol should be as conservative as possible with less reduction of teeth structure and greater esthetics and longevity [9]. The shade of maxillary teeth was selected as 1M1using Vita 3D master and the preparations were performed with diamond burs for incisors canines and premolars and finish line for each tooth was a deep chamfer and respecting the shared preparation principles in the anterior and posteriors regions for all systems (i.e., single-unit and FPD abutment) include an incisal/occlusal reduction of $1.5 \mathrm{~mm}$ 
to $2 \mathrm{~mm}$ [10]. These are the minimal recommended reduction. Increasing the amount of incisal reduction in the anterior region to $2 \mathrm{~mm}$ gives the dental technician enough room to develop a natural esthetics (Figure 6).

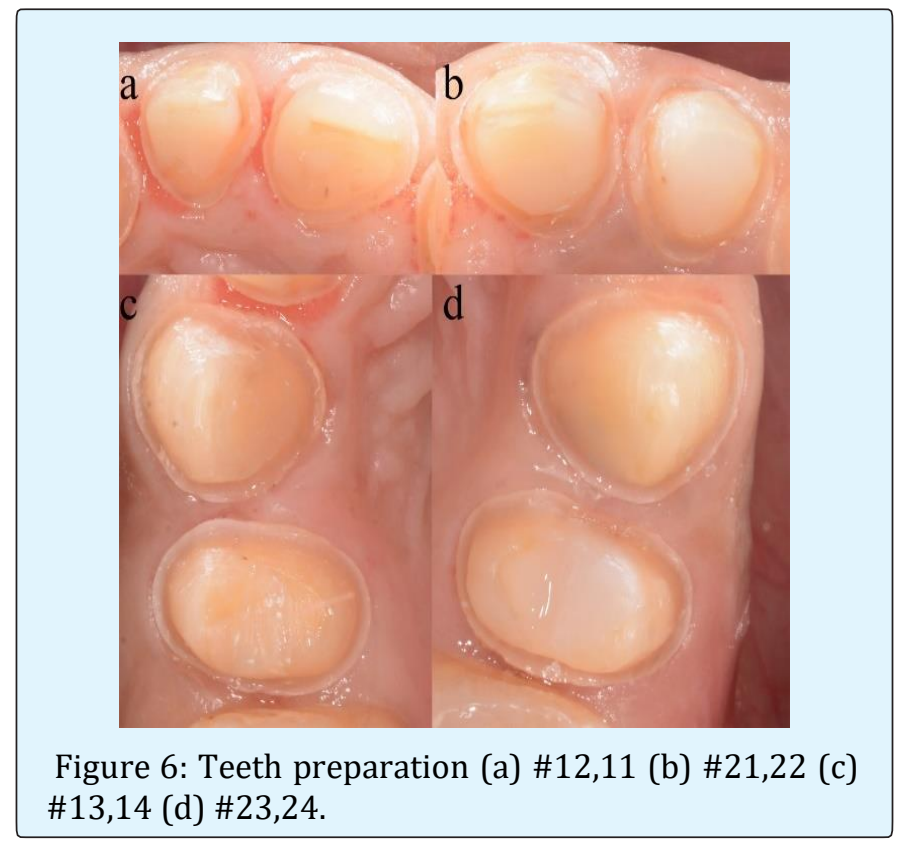

The interim restorations (Figure 7) were carried out with resin acryl (protemp) by direct technique and aimed to restore esthetics and occlusal scheme to incorporate a definitive prosthesis in future and it provided time for evaluation of design and occlusal form before deciding to proceed with definitive restoration. Long term provisionalization should be employed when concerns exist regarding initial health and stability of the gingiva, and to ensure esthetics, occlusion, and phonetics $[11,12]$. Proper temporization with proper contours along with the increased awareness of patient's oral hygiene showed a great improvement of the gingival inflammation.

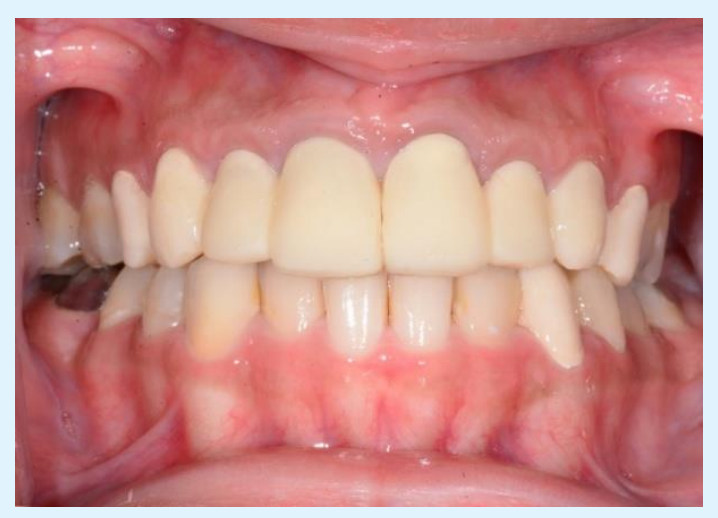

Figure 7: interim crowns showing improved gingival condition.
The patient had a substandard root canal treatment (RCT) in teeth \#12, 11, 21\& 22. Root canal retreatment was carried out and $5 \mathrm{~mm}$ obturation was left to provide good apical seal and leaving the post space. Fiberposts (ParaPost White, PP, Coltène/Whaledent) were cemented to retain the composite core using the dual cure luting agent Rely X U 200(3M ESPE) according to the manufacturer instructions. After an esthetic evaluation (color, shape, size and position of teeth) and functional checking (anterior guidance, phonation), a gingival retraction was carried out using an impregnated cord (23\% aluminum chloride) and a final impression was taken using polyvinyl siloxane (Virtual, IvoclarVivadent) (Figure 8) and sent to the laboratory [13]. In the lab all full coverage crowns were fabricated by lithium disilicate (Ips-emax Press) using pressing technique (Ips-emax ingots)

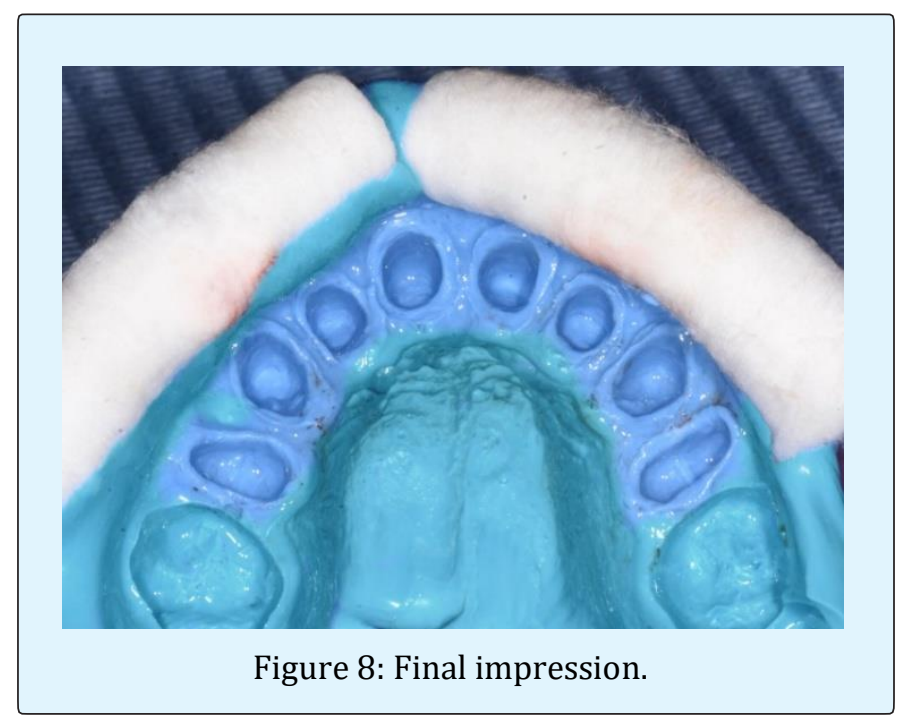

In the clinic the bisque was checked to evaluate esthetics, shade, marginal fit, and proximal contacts. On the other hand centric and eccentric occlusion and phonation were verified. Once patient approval was insured, glazing was performed in the lab. Before cementation, care must be taken to the order of the eight crowns seating in the arch which could jeopardize their correct path of insertion. After etching the inner surfaces of the disilicate crowns with $10 \%$ of hydrofluoric acid for 20 seconds and drying, a coat of silane coupling agent was applied for 1 minute [14]. On the other hand the abutments were cleaned to be sure that temporary cement is removed. According to the manufacturer instruction etching \& bonding was unnecessary. Finally the cementation of the crowns was performed by a dual cure luting agent Rely X U 200(3M ESPE) using the quarter technique (Figures 9-11). 

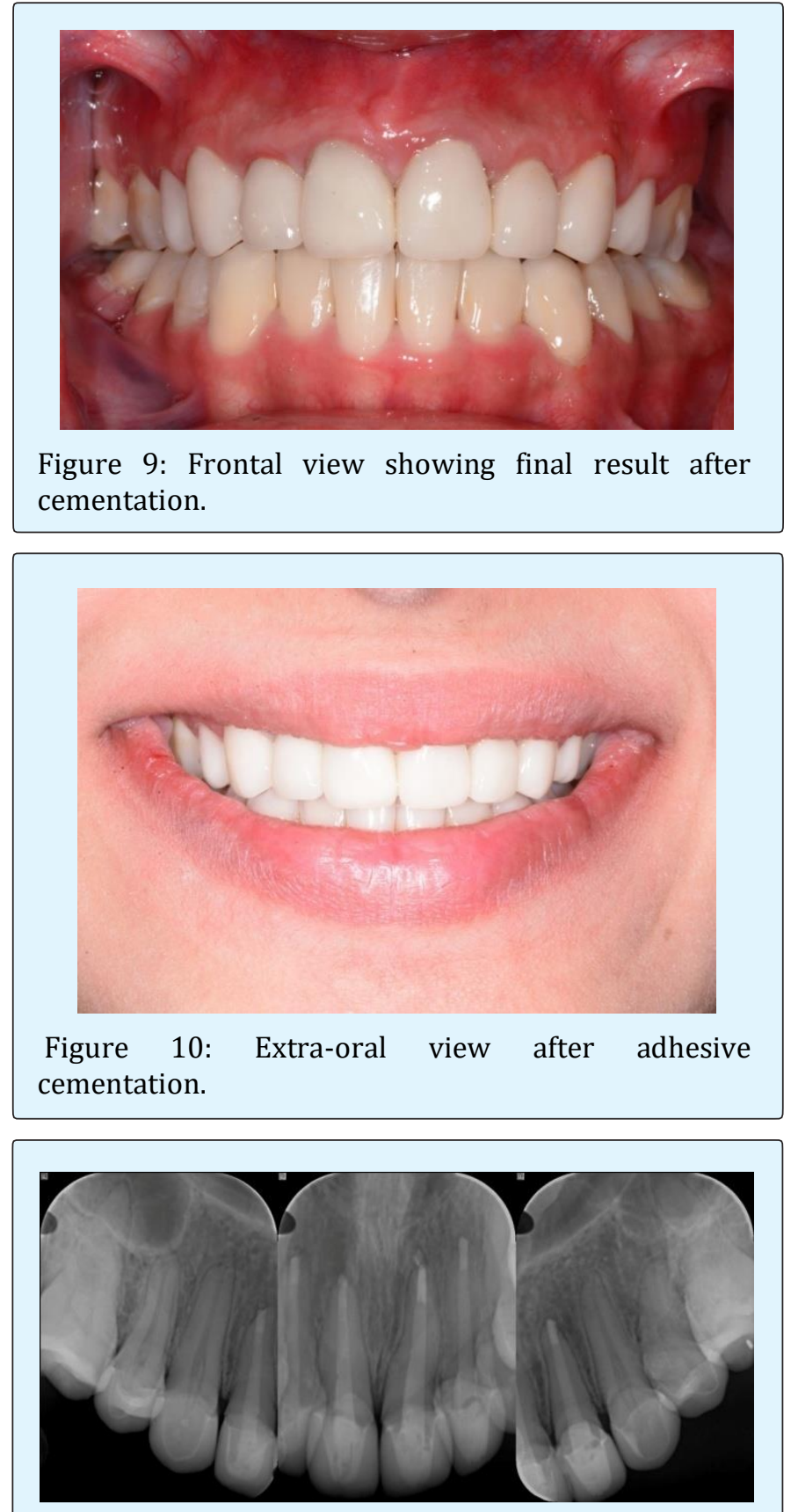

Figure 11: Post-operative radiographs.

\section{Discussion}

Dento-Facial esthetics has been used to describe the inter-relationship between the face, lips, gingival and teeth in obtaining an overall esthetic result $[15,16]$. Smile rejuvenation can positively impact a patient's self-esteem and emotional health through improved appearance [17]. Excellent soft tissue health and correct tooth contours and emergence profiles are just as important as the actual color of the new restoration/adjacent teeth $[18,19]$. For more than three decades metal ceramic restorations have been the choice thanks to their predictable performance and reasonable esthetics. Metal-ceramic prostheses are widely accepted and are the most commonly used extracoronal restoration $[20,21]$ because they combine the strength of the metal and the esthetic quality of the ceramic material [21-23].

Nevertheless they presented many problems such as Low translucency due the increased light reflectivity from the opaque porcelain used to mask the metal substructure $[24,25]$ and problems of metal-ceramic bonding, corrosion (galvanism) and risk of gingival discoloration (tattooing). Another problem is the light gray discoloration that often occurs at the adjacent gingival tissues due to the increased reflectivity exhibited by metal ceramic restorations [26].

Despite their success the demand of improved esthetic has led to introduction of all ceramic restorations $[27,28]$. Bonded composite core require the presence of a minimum of 1.5-2 $\mathrm{mm}$ height of ferrule after crown preparation [28]. In this case the remaining sound dentin (ferrule) was $2 \mathrm{~mm}$, thus restoring with fiber post and composite core was selected and was a suitable option under lying vitro ceramic crowns.

In this case report and due to the thickness, color stability of the Lithium disilicate (E-max press) based crowns, it is unnecessary to use the try-in paste prior to cementation to simulate the cement color. E-MAX ceramic crowns are preferable type of crowns due to their esthetic appearance and high strength of $470 \mathrm{MPa}$. They are translucent in color, which ensures the closest match of light properties of natural teeth and eliminate the ugly metal band around the gum line that is characteristic of metal ceramic crowns. Bacterial plaque accumulation has also been reported to be less on porcelain margins as compared to metal margins $[29,30]$. On another hand Dental porcelain must be glazed or highly polished [31] because it is more abrasive of enamel than of other restorative materials (e.g., gold or amalgam [32,33] and has been implicated in severe occlusal wear.

\section{Conclusion}

Today, patients are increasingly interested in metalfree restoration. Glass-ceramics are particularly suitable for fabricating crowns with esthetically pleasing outcome. In this case the stability of the periodontal tissues, occlusion, phonetics and esthetics were insured by performing a long term Provisionalization. Lithium 


\section{Open Access Journal of Dental Sciences}

disilicate crowns in esthetic zone can permit highly esthetic solutions such as color correction/matching and allow us to perform correct shapes. Well-made Lithium disilicate (E-max press) based crowns provide some of the most esthetically pleasing restorations currently available. They can be virtually indistinguishable from unrestored natural teeth and alloy to achieve predictable outcomes in challenging situations.

\section{Acknowledgment}

The author wishes to thank Professor Jilani Saafi for the great help and support in preparing this case report.

\section{References}

1. Canadian Agency for Drugs and Technologies in Health (2015) Porcelain-Fused-to-Metal Crowns versus All-ceramic Crowns: A Review of the Clinical and Cost-Effectiveness [Internet]. Ottawa (ON): CADTH Rapid Response Reports.

2. Ritter RG, Rego NA (2009) Materials consideration for using lithium disilicate as a thin veneer option. Journal of Cosmetic Dentistry 25(3): 111-117.

3. Soares PV, Spiniphr MS, Carvalho VF, Gomes SP, Gonzaga RC, et al. (2014) Esthetic rehabilitation with laminated ceramic veneers reinforced by lithium disilicate. Quinessence Int 45(2): 129-133.

4. Walter RD, Raigrodski AJ (2008) Critical appraisal: clinical considerations for restoring mandibular incisors with porcelain laminate veneers. J Esthet Restor Dent 20(4): 276-281.

5. Guess PC, Stappert CF, Strub JR (2006) Preliminary clinical results of a prospective study of IPS e.max Press- and Cerec ProCAD- partial coverage crowns. Schweiz Monatsschr Zahnmed 116(5): 493-500

6. Seghi RR, Sorensen JA (1995) Relative flexural strength of six new ceramic materials. Int J Prosthodont 8(3): 239-246.

7. McLaren EA (1998) All-ceramic alternatives to conventional metal-ceramic restorations. Compend Contin Educ Dent 19(3): 307-308.

8. Bradleyj Olson (2012) Restoration of a fractured central incisors. Compendium 33(3).

9. Asbia S, Saafi J (2017) Smile design (Review). African journal of dentistry and implantology 9: 11-28.
10. Raigrodski AJ (2003) Clinical and laboratory considerations for the use of CAD/CAM Y-TZP-based restorations. Pract Proced Aesthet Dent 15(6): 469476.

11. Malone W, Koth D, Cavazo E, Kaiser DA, Morgano SM, et al. Theory and Practice of Fixed Prosthodontics, $8^{\text {th }}$ (Edn.), St. Louis, Ishiyaku Euro-America pp: 71-87.

12. Rahul K, Archana D, Rahul G, Nandita B, Venu V, et al. (2016) To Splint or Not to Splint: The Current Status of Periodontal Splinting. J Int Acad Periodontol 18(2): 45-56.

13. Saafi J, Debbabi I, Chakroun M, Nouira Z, Harzallah $\mathrm{BH}$, et al. (2017) Esthetic Restoration of Two Severely Decayed Maxillary Central Incisors: A Case Report. J Oral Health Dent Sci 1(1): 104.

14. Gandhi KN, Sabita RM, Shah MP ( 2016) Rejuvenating Smile with All Ceramic Crowns. J Contemp Dent 6(1): 80-84.

15. McLaren E, Rifkin R (2005) Macroesthetics: Facial and Dentofacial Analysis. Oral Health 95(11): 65-77.

16. Wells D (1999) The lateral Incisor: the Unsung Hero in Smile Design AACD Journal of Cosmetic Dentistry 15(3): 38-46

17. Rosenthal L (1995) Aesthetic Smile Enhancement Using Porcelain Laminate Veneers Practical Periodontics and Aesthetic Dentistry Winter Supplement 2-8

18. Jones L (2007) The Art of Matching Select Porcelain Restorations to the Anterior Teeth: Accreditation Case Type II (One or Two Indirect Restorations) Managing Contextual Color Variances AACD. Journal of Cosmetic Dentistry Fall 23(3): 38-41.

19. Magne P, Belser U (2002) Bonded Porcelain Restorations in the Anterior Dentition: A Biomimetic Approach Quintessence Pub Hanover, IL.

20. Christensen GJ (1986) The use of porcelain-fusedtometal restorations in current dental practice: A survey. J Prosthet Dent 56(1): 1-3.

21. Seymour KG, Samarawickrama DY, Lynch EJ (1999) Metal ceramic crowns a review of tooth preparation. Eur J Prosthodont Restor Dent 7(2): 79-84. 
22. Yamamoto M (1985) Metal-ceramics: principle and methods of Makoto Yamamoto. Chicago: Quintessence pp: 15-22, 2682-91.

23. Castellani D, Baccetti T, Giovannoni A, Bernardini UD (1994) Resistance to fracture of metal ceramic and all-ceramic crowns. Int J Prosthodont 7(2): 149-154.

24. Chiche GJ, Pinault A (1994) Esthetics of anterior fixed prosthodontics. Chicago: Quintessence; pp: 97-98.

25. Wall JG, Cipra DL (1992) Alternative crown systems. Is the metal-ceramic crown always the restoration of choice? Dent Clin North Am 36(3): 765-782.

26. Geller W, Kwiatkowski SJ (1987) The Willi's glass crown (1987): a new solution in the dark and shadowed zones of esthetic porcelain restorations. Quintessence Dent Technol 11(4): 233-242.

27. Kelly JR, Benetti P (2011) Ceramic materials in dentistry: historical evolution and current practice. Aust Dent J 56(1): 84-96.

28. Hatai Y (2014) Extreme masking: achieving predictable outcomes in challenging situations with lithium disilicate bonded restorations. Int J Esthet Dent 9(2): 206-222.

\section{Open Access Journal of Dental Sciences}

29. Ng CC, Dumbrigue HB, Al-Bayat MI, Griggs JA, Wakefield CW (2006) Influence of remaining coronal tooth structure location on the fracture resistance of restored endodontically treated anterior teeth. J Prosthet Dent 95(4): 290-296.

30. Koidis PT, Schroeder K, Johnston W, Campagni W (1991) Color consistency, plaque accumulation, and external marginal surface characteristics of the collarless metal-ceramic restoration. J Prosthet Dent 65(3): 391-400.

31. Al-Wahadni AM, Martin DM (1999): An in vitro investigation into the wear effects of glazed, unglazed and refinished dental porcelain on an opposing material. J Oral Rehabil 26(6): 538-546.

32. Monasky GE, Taylor DF (1971) Studies on the wear of porcelain, enamel, and gold. J Prosthet Dent 25: 299.

33. Ramp MH, Suzuki S, Cox CF, Lacefield WR, Koth DL (1997) Evaluation of wear: enamel opposing three ceramic materials and a gold alloy. J Prosthet Dent 77(5): 523-530. 